\title{
Mapeamento das Características do Terreno em Ambiente Virtual como Ferramenta de Apoio ao Ensino Militar
}

\author{
Raphael de Souza e Almeida ${ }^{1,2}$, Alexandre de Menezes Villarmosa ${ }^{2}$, Alberto Barbosa Raposo ${ }^{1}$ \\ ${ }^{1}$ PUC-Rio, ${ }^{2}$ Marinha do Brasil \\ Rio de Janeiro/RJ - Brasil \\ rsalmeida@tecgraf.puc-rio.br, alexandremvilla@gmail.com, abraposo@tecgraf.puc-rio.br
}

\begin{abstract}
Resumo: Este estudo apresenta o SVETT (Simulador de Estudo Topotático do Terreno), um simulador criado com o intuito de auxiliar os alunos dos Cursos de Aperfeiçoamento Avançado do Corpo de Fuzileiros Navais. O SVETT permite recriar uma região qualquer no globo terrestre onde é possível inserir o aluno nesta área e, com os recursos visuais disponibilizados ao instrutor, possibilita maior facilidade na transmissão de seus conhecimentos. Avaliamos o simulador com 12 usuários, sendo 5 instrutores e 7 alunos, obtendo resultados satisfatórios no que diz respeito à aprendizagem e usabilidade tanto para os alunos como para os instrutores.
\end{abstract}

Palavras-chave: Realidade virtual; Experiência do usuário; Ambiente de treinamento sintético.

\section{Introdução}

A Marinha do Brasil estabelece, entre outras tarefas de sua Doutrina Básica, a constante prontidão para atuar na garantia dos poderes constitucionais e, por iniciativa de qualquer destes, da lei e da ordem [1], cabendo estas operações à Força de Fuzileiros da Esquadra [2], composta pelo Corpo de Fuzileiros Navais (CFN), que encontra-se permanentemente em condição de pronto emprego, assegurar sua capacidade de projeção de poder do mar para a terra [3]. Para que as tarefas citadas sejam cumpridas da melhor maneira possível, um planejamento detalhado e bem estruturado se faz necessário [4]. Seu preparo é feito por pessoal altamente treinado e capaz de interpretar todos os dados disponibilizados, que envolvem normalmente aspectos relacionados ao relevo, inimigo, vegetação e clima, conhecidos como aspectos Topotáticos [5].

Ensinar a militares esse tipo de atividade por vezes é difícil dentro de uma sala de aula fechada. Por isso os alunos são normalmente levados a diferentes regiões, de forma que possam ter um melhor contato com o terreno e entender o que deve ser considerado para seu estudo. Esses deslocamentos, por vezes distantes e sem apoio logístico da unidade, geram custos elevados com pessoal e material.

Baseado na tendência mundial onde o desenvolvimento de diferentes categorias de simuladores [6], pela imersão em um Ambiente Sintético de Treinamento (modelos gerados por computador para os participantes experimentarem e interagirem intuitivamente em tempo real [7]) reproduzido com precisão, o primeiro contato com o terreno poderia ser feito já em sala de aula. Nesse sentido propomos o Simulador Virtual para Estudo Topotático do Terreno (SVETT). Um simulador (a simulação utiliza a modelagem baseada em um sistema computacional para criar um programa, que representa o todo ou uma parte de um processo [8]), através da utilização em realidade virtual de recursos instrucionais normalmente encontrados em sala, tem a finalidade de facilitar a transmissão de conhecimento do instrutor, bem como unificar o entendimento dos alunos. O objetivo deste estudo é avaliar se o uso dos diferentes recursos disponíveis contribuem para a aprendizagem dos usuários.

A próxima seção apresenta a motivação para o estudo. Na seção posterior elucidaremos trabalhos relacionados. Em seguida, descrevemos a solução proposta e falaremos sobre a avaliação. Posteriormente, versaremos sobre os resultados obtidos, analisando-os concomitantemente. Finalizando, mencionaremos trabalhos futuros e as conclusões.

\section{Motivação}

Para iniciar o conteúdo, precisamos entender o processo onde procuramos observar as características do terreno que pode influenciar decisivamente as ações em um certo local, conhecido como "Giro do Horizonte".

Por definição, “Giro do Horizonte” é a identificação em uma Carta Militar (CM) dos vários pontos do terreno, que é formado até a linha do horizonte. Esta linha é limitada a uma distância de 4 quilômetros por causa da dificuldade de observar além desta distância sem equipamentos adequados.

Este estudo facilita o entendimento à medida que observamos as principais características da região e sua conformação. Após esta fase iniciamos o estudo tático do terreno, onde efetuamos uma série de comparações entre faixas do terreno com a finalidade de melhor explorá-lo. Importante ressaltar que, por não ser possível posicionar os meios no terreno antes de uma operação militar, existe a necessidade de se "imaginar" os aspectos militares tais como Unidades Militares e instalações, entre outros.

Para a realização dos exercícios no terreno real, alguns fatores devem ser considerados, entre eles disponibilidade de tempo no calendário escolar para os preparativos e execução do exercício, custos envolvidos tanto para acomodação como alimentação e deslocamento, além da disponibilidade de pessoal e meios para apoiar em atividades como transporte e segurança dos alunos e equipes. Por exemplo, para viabilizar a viagem, há custos de compra de passagens, hospedagem, combustível e alimentos. Tomando como base o Curso de Aperfeiçoamento Avançado dos Oficiais do Corpo de Fuzileiros Navais da Marinha do Brasil, em vários treinamentos visitando 9 regiões diferentes, são gastos cerca de $\mathrm{R} \$ 550.000,00$ para uma média de 35 alunos e 15 instrutores.

\section{Trabalhos Relacionados}

Horst Liske [9] demonstra a validade em utilizar treinamentos baseados em computador (do inglês Computer-Based Training - CBT) como forma de fixar o 
conteúdo tendo como a finalidade o preparo para futuras avaliações. Ele conclui em seu trabalho que a utilização dessa plataforma fornece uma boa visão geral do conhecimento adquirido pelos alunos em algumas áreas. Esse conceito utilizado entre as aulas e o exercício no terreno real como forma de verificação da aprendizagem permite que as dúvidas que antes apareciam somente nos exercícios propriamente ditos apareçam antes, aumentando a qualidade do adestramento.

Maarten van Veen [10], em seu livro, aborda diversos aspectos relativos à validação de adestramentos utilizando os seguintes tipos de simulação: viva, quando pessoas de verdade operam sistemas de armas de verdade, Virtual, quando pessoas de verdade estão em um ambiente virtual, e construtiva, quando existe a simulação de tropas operando em um ambiente simulado. São enfatizadas nesta publicação ainda aspectos como a influência do realismo da simulação com a finalidade de preparar o militar para o combate, possibilitando, por vezes, que este entre em conflito armado sem hesitação. Ele discorre também as formas de validação e, entre elas, destaca que na validação militar os simuladores são adquiridos ou até mesmo construídos pelos militares para resolver um problema específico.

Kay Palkhivala et al. [11] descrevem as estratégias para a criação de plataformas para treinamento baseado em computador, onde citam diversas observações sobre sistemas de aprendizagem. Neles foram constatados que as preferências para os métodos de aprendizagem dos usuários são aulas individuais, seguindo uma aula estruturada, a observação de uma demonstração, usando um manual ou descobrindo por si mesmo. Outro fato encontrado foi que as pessoas gostam se ser entretidas por vídeos, respostas personalizadas e interações interativas.

Alex W. Stedmon et al. [12], em seu estudo, versa sobre a importância do treinamento em simuladores como ferramenta de capacitação para os militares. Em conjunto com o exame da ergonomia cognitiva da Realidade Aumentada, foi realizado um trabalho adicional sobre o potencial de feedback de treinamento em uma tarefa complexa de tomada de decisão baseada em atividades reais envolvendo Operações Navais. Além deste estudo foi desenvolvido e discriminado, com uma Força Aérea e dois exemplos navais, o atual estágio de implementação de tecnologias de ambiente virtual em treinamento militar. Como ficou evidente, o treinamento avançado ainda usa realidade virtual e é usado principalmente como parte de cursos de treinamento avançado, em vez de integrado ao ambiente de trabalho operacional.

Baseado nos resultados desses estudos constatamos que, em linhas gerais, eles se complementam e fornecem conceitos importantes para a criação de uma experiência agradável. Com a finalidade de conceber uma simulação que contemplasse soluções para o problema proposto, foram criadas ferramentas que possibilitam uma melhor interação entre o instrutor e os alunos, conforme apresentada a seguir.

\section{SVETT - Simulador de Estudo Topotático do Terreno}

O SVETT é um simulador utilizado para o estudo dos aspectos topológicos e táticos do terreno, conhecido como aspectos Topotáticos (aspectos topológicos são entendidos como as conformações dos relevos de uma determinada região, já os aspectos táticos, são estudos voltados à utilização desse relevo com a finalidade de se aproveitar suas características para se obter sucesso no cumprimento de uma tarefa estabelecida, que pode ser derrotar um inimigo ou até mesmo estabelecer uma posição defensiva). A plataforma, criada usando a game engine Unity 3D (https://unity.com), é dividida em duas interfaces: uma primeira, a ser utilizada pelo instrutor, que, por não utilizar realidade virtual pode vir a ser um laptop, desktop ou tablet, e a outra, a ser utilizada pelo aluno, utiliza um Head Mounted Display (HMD) com a finalidade de observar as informações enviadas pelo instrutor. Detalhes sobre os recursos e interações disponíveis são descritos a seguir.

\subsection{Interface do Instrutor}

Tanto instrutor como aluno possuem a observação da mesma região do globo terrestre, escolhida em função do potencial de conhecimento que esta área pode ajudar a fornecer. Por se tratar de uma aplicação a ser utilizada entre o período de ensinamentos teóricos e a prática, normalmente esses locais são regiões a serem futuramente visitadas. A diferença está na interface: no caso do instrutor, este observa uma carta topográfica (cartas confeccionadas mediante um levantamento topográfico regular ou compiladas de cartas topográficas existentes e que incluem os acidentes naturais e artificiais, permitindo facilmente a determinação de altitudes [12]) da região a ser estudada, tendo a posição do aluno marcada com a bandeira do CFN (Figura 1). Outras telas disponíveis são: um quadro branco que possibilita confeccionar desenhos e uma tela onde é possível projetar slides. Nos dois últimos casos, ambos são projetados no ambiente do aluno de forma diegética, inserindo as informações necessárias ao usuário em algum elemento que faça parte do ambiente [13].

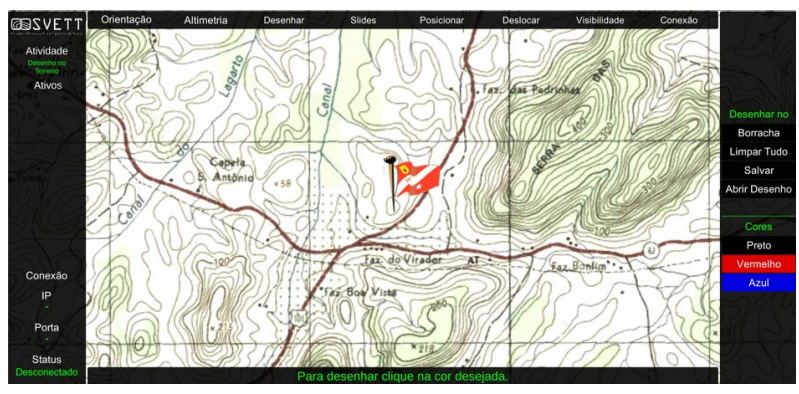

Figura 1. Interface utilizada pelo instrutor exibindo a opção para desenhar no terreno.

\subsection{Interface do Aluno}

O aluno é inserido no Ambiente Sintético de Treinamento onde ele observa o terreno produzido, observado na figura 2, por meio do HMD, neste caso, o OCULUS Rift (https://www.oculus.com/). Nele o aluno é capaz de interagir com os objetos próximos, tais como carta topográfica, slides e quadro branco, quando disponibilizados. Ele também é capaz de apontar para posições no terreno através de um apontador laser lançado a partir de sua mão. O terreno é produzido utilizando o asset "Real World Terrain" (https://assetstore.unity.com/packages/tools/terrain/real- 
world-terrain-8752), utilizado pela Unity 3D. Este recurso utiliza fonte aberta, neste caso o site Open Street Maps (https://www.openstreetmap.org/), para obter os dados relativos ao relevo e imagens, gerando um terreno onde as imagens de satélite são ajustadas ao relevo na forma de texturas.

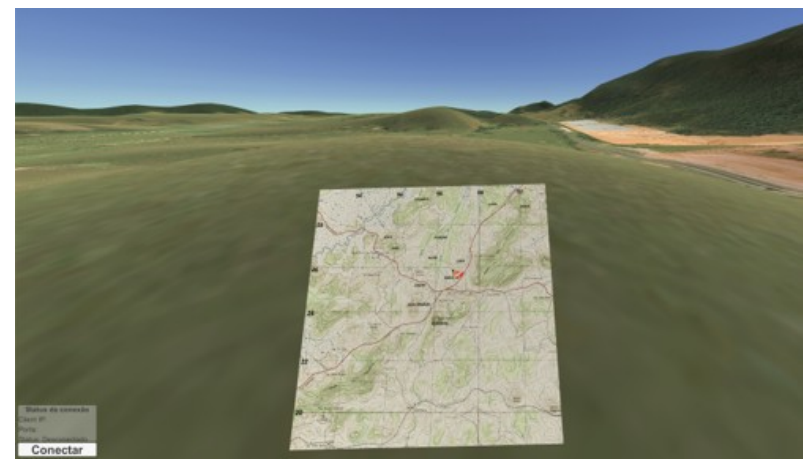

Figura 2. Interface utilizada pelo aluno observando o terreno e a carta disponibilizada.

\subsection{Recursos Instrucionais}

Para a orientação no terreno os alunos são capazes de observar os pontos cardeais, assim como qualquer localização ou direção apontada pelo Instrutor. Além disso, quadrículas (série de linhas retas que se cruzam a intervalos regulares, formando quadrados que podem ser facilmente designados pelos números indicativos das retas que se cruzam no seu canto inferior esquerdo [5]) da carta topográfica poderão ser projetadas no terreno, dando uma noção distância. Para facilitar seu estudo e navegação foi disponibilizada uma carta militar onde uma bandeira do Corpo de Fuzileiros Navais indica a posição do Observador.

Uma maneira de estudar os aspectos táticos do terreno é iluminando elevações cuja importância nas ações está em servir de referência para transmissão de informações. Na aplicação é possível iluminar elevações previamente programadas, facilitando o estudo. Outro tipo de iluminação está na possibilidade de inserir desenhos, que podem ser feitos pelo instrutor em sua carta militar e projetados no terreno para o aluno, permitindo melhor observação. Isto servirá para ressaltar aspectos do terreno tais como hidrografia, planimetria e estradas, bem como exibir medidas de coordenação entre outros.

Outros recursos instrucionais estão disponíveis caso explicações com projeções no terreno não esclareçam as dúvidas. Existindo a necessidade de efetuar desenhos em um quadro branco, este poderá ser exibido e manipulado, bem como o instrutor, com a disponibilidade de slides de uma apresentação, poderá exibi-los para conduzir as explicações. Além destes é possível transmitir a noção do posicionamento de tropas e simular interações entre forças por meio de animações no terreno.

Com a finalidade de transmitir as dificuldades atinentes ao posicionamento e observação, alterações na visibilidade e na localização dos alunos são possíveis. Assim, a opção de poder se posicionar em um local e tentar observar possíveis deslocamentos, bem como movimentar-se na rota pela qual a tropa passaria torna a experiência melhor e traz mais benefícios no contexto da instrução.

\section{Avaliação}

Realizamos uma avaliação do SVETT com 5 instrutores e 7 alunos a fim de identificar se o uso dos diferentes recursos disponíveis contribuem para a aprendizagem dos usuários. Avaliamos dois cenários para os alunos e um cenário para os instrutores.

Para o instrutor, o contextualizamos em uma aula e solicitamos que ele utilizasse o equipamento para transmitir seu conhecimento.

Já para os alunos foram utilizados dois cenários, onde eles tiveram uma instrução tanto no terreno (normalmente executado durante o processo ensino aprendizagem) como no simulador, divergindo apenas na ordem em que foram executados. Neste caso, chamaremos de "SVETT" o cenário onde 4 dos 7 alunos passam primeiro pelo simulador e, posteriormente vão ao exercício real e "terreno" o cenário onde 3 dos 7 alunos passam primeiro pelo exercício no terreno e depois pelo simulador (Figuras 3 e 4).

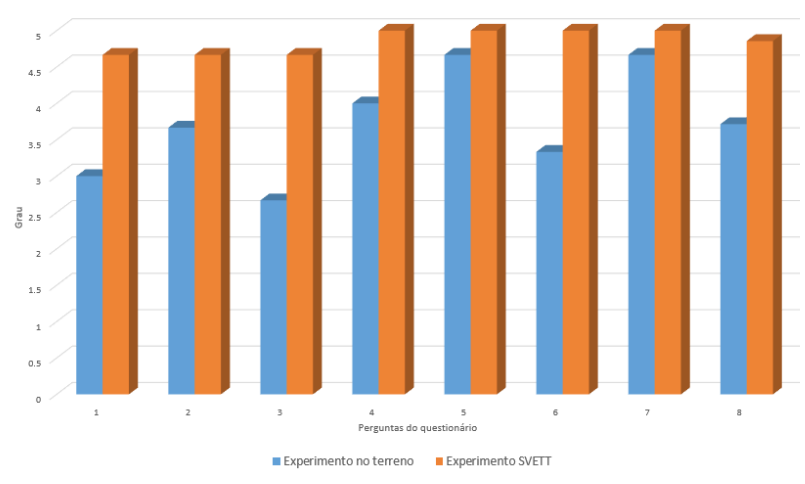

Figura 3. Gráfico contendo as médias das respostas individuais dos alunos.

\begin{tabular}{|c|l|}
\hline 1 & A condução do giro do horizonte foi... \\
\hline 2 & O entendimento do estudo tático do terreno foi... \\
\hline 3 & Receber instrução através da utilização dos recursos instrucionais (quadro branco ou slides) foi... \\
\hline 4 & A observação do terreno foi... \\
\hline 5 & De modo geral em achei a ferramenta de instrução... \\
\hline 6 & Receber instrução com essa ferramenta foi... \\
\hline 7 & Com relação às respostas que deste neste questionário, eu estou.... \\
\hline 8 & Média Final \\
\hline
\end{tabular}

Figura 4. Índice das perguntas feitas aos alunos.

\section{Resultados e Análise}

Os resultados constataram uma melhora no processo de aprendizagem dos alunos. No cenário "SVETT”, onde o tempo de intervalo entre os experimentos foi de oitenta e dois dias, os alunos, por ocasião da segunda entrevista, reportaram terem se lembrado das perguntas realizadas bem como reconheceram o terreno. Além disso, por ocasião do término dos experimentos foi perguntado se os alunos estavam sentindo algum tipo de dor de cabeça, o que foi negado por todos.

Os instrutores relataram como aspectos positivos a possibilidade de utilizar os recursos normalmente disponibilizados em sala e sua facilidade de uso, além 
de deixar o entendimento muito interessante, onde podemos inferir a boa aceitação por parte dos destes. Um aspecto negativo relatado foi a dificuldade em observar o rosto do aluno, o que facilitaria a detecção se este está com dúvida.

\section{Conclusão}

Neste estudo apresentamos o SVETT, um simulador virtual de estudo topotático do terreno que utiliza fontes abertas para reproduzir uma região qualquer e inserir tanto o aluno como o instrutor em uma área através de suas interfaces, com finalidade de majorar o ganho de conhecimento e preparar alunos para um melhor desempenho em exercícios militares.

Avaliamos nossa aplicação com 12 participantes, entre alunos e instrutores, onde obtivemos resultados favoráveis no processo ensino-aprendizagem. Através de dados coletados por meio de entrevistas e questionários, todos os alunos que passaram pelo simulador identificaram facilmente a região ao chegarem ao local propriamente dito, bem como se lembraram das questões realizadas na primeira etapa.

Nossa solução é adequada à medida que tanto docentes acharam a ferramenta fácil de usar, como discentes absorveram conhecimento, fato comprovado com a lembrança adquirida fruto do uso do simulador. Os resultados sugerem também melhorias para que o simulador seja adequado para todo tipo de usuário, além de uma proposta de estudos futuros, como a possibilidade da identificação, mesmo utilizando o HMD, da expressão do rosto do usuário, bem como a possibilidade da transmissão da instrução para alunos localizados em diferentes Unidades Militares.

\section{Bibliografia}

[1] Armada, E. M. (2014) Doutrina Básica da Marinha. Estado-Maior da Armada, Brasília, 2a Revisão.

[2] Brasil (2012) Livro Branco de Defesa Nacional'. Ministério da Defesa, Brasília. Online: https://www.defesa.gov.br/arquivos/estado_e_defesa/livro_branco /livrobranco.pdf

[3] Ministério da Defesa (2012) Política Nacional de Defesa Estratégia Nacional de Defesa. Brasília. Online: https://www.defesa.gov.br/arquivos/estado_e_defesa/ENDPND_Optimized.pdf

[4] Marinha do Brasil (2008) Manual de planejamento dos Grupamentos Operativos de Fuzileiros Navais. Comando-Geral do Corpo de Fuzileiros Navais, Rio de janeiro, 1a edição.

[5] Marinha do Brasil (2008) Manual do Combatente Anfíbio. Comando-Geral do Corpo de Fuzileiros Navais, Rio de Janeiro, 1a edição.

[6] Arbia, D. B.; Ouersighni, R. (2012) Simulation Systems for armed forces training. Proc. International Conference on Computer Related Knowledge, Sousse, Tunisia.

[7] Stedmon, A. W.; Stone, R. J. (2001) Re-viewing reality: Human factors of synthetic training environments. Int. J. of HumanComputer Studies 55(4): 675-698. Academic Press. DOI: 10.1006/ijhc. 2001.0498

[8] Abreu, C. E. M.; Gonzaga, D. R. B.; Santos, F.J.; Oliveira, J.F.; Oliveira, K. D. M. et al. (2017) Indústria 4.0: Como as Empresas Estão Utilizando a Simulação para se Preparar para o Futuro. Revista Ciências Exatas e Tecnologia 12(12): 49-53. DOI: 10.17921/1890-1793.2017v12n12p49-53

[9] Liske, H. (2010) A Lightweight Model of Computer Based Training for Exam Preparation. Proc. Int. Conf. on Computer Systems and Technologies, p. 365-369, ACM. DOI: $10.1145 / 1839379.1839444$

[10] Veen, M. V. (2014) Validating the virtual: An Extensive Case Study of a Military Training Simulator. 280 pp. Dissertação. UvH Universiteit voor Humanistiek. Online: https://repository.uvh.nl/handle/11439/381

[11] Palkhivala, K.; Bowllan, C.; Barnwell, T. (2003) CBT on the fast track. Proc. 17th Annual Int. Conf. Computer Documentation. Pp 169-175. ACM. DOI: https://doi.org/10.1145/318372.318585

[12] Anderson, P. S. (1982) Princípios de Cartografia Básica.

[13] Bailer, F. S.; and Alves, A. G. (2018) Boas práticas em Realidade Virtual Imersiva. Proc. SBGames 2018, p. 88-96. SBC. 